\title{
Evaluation of Dentinal Crack Initiation after Root Canal Preparation Using three Different Nickel Titanium Rotary Instrument: An In Vitro Study
}

${ }^{1}$ RS Basavanna, ${ }^{2}$ Vasundhara Shivanna, ${ }^{3}$ Juhi Ku Nayak

\begin{abstract}
Objectives: To evaluate the incidence of dentinal crack initiation after root canal preparation using four different nickeltitanium $(\mathrm{NiTi})$ rotary instruments.

Methods: Sixty single-rooted premolars were selected. A total of 15 teeth were left unprepared and served as a negative control; another 25 teeth were instrumented with the ProTaper universal system up to size F2 as a positive control, and the remaining 30 teeth were shaped with the following experimental groups with an apical size 25 file: ProTaper Next X2 and K3XF $25 / 0.4$. Canals were irrigated with $12 \mathrm{~mL}$ of $1 \%$ sodium hypochlorite solution and rinsed with $5 \mathrm{~mL}$ of distilled water. All the roots were sectioned perpendicular to the long axis at 3, 6 and 9 $\mathrm{mm}$ from the root apex and examined under a stereomicroscope at $25 \mathrm{X}$ magnification to determine the presence of cracks. Data were analyzed using Fischer's exact test.
\end{abstract}

Results: There was a non-significant difference in the percentage of dentinal crack after biomechanical preparation with $\mathrm{NiTi}$ rotary files as compared to the unprepared group except when compared with protaper universal.

Interpretation and conclusion: All NiTi rotary files are capable of initiation of cracks during root canal instrumentation. The maximum percentage of cracks occur in the apical section. The percentage of dentinal crack in the apical section is least in ProTaper Next.

Keywords: Dentinal cracks, ProTaper next, ProTaper universal, K3XF, Root canal instrumentation, Vertical root fracture, Rotary Nickel-Titanium instruments.

How to cite this article: Basavanna RS, Shivanna V, Nayak JK. Evaluation of Dentinal Crack Initiation after Root Canal Preparation Using three Different Nickel Titanium Rotary Instrument: An In Vitro Study. CODS J Dent 2017;9(1):10-15.

Source of support: Nil

Conflict of interest: None

\section{INTRODUCTION}

Successful endodontic therapy depends upon the triad of proper diagnosis, through biomechanical preparation and three-dimensional (3-D) obturation of root canal system. The irrevocable aim of endodontic instrumenta-

\footnotetext{
${ }^{1}$ Professor, ${ }^{2}$ Principal and HOD, ${ }^{3}$ Postgraduate Student

${ }^{1-3}$ Department of Conservative Dentistry and Endodontics, College of Dental Sciences, Davangere, Karnataka, India,

Corresponding Author: Juhi Ku Nayak, Postgraduate Student, Department of Conservative Dentistry and Endodontics, College of Dental Sciences, Davangere, Karnataka, India, e-mail: nayakjuhi08@gmail.com
}

tion is to completely remove microorganisms, debris, and tissue by enlarging the canal diameter and create a canal form that allows a proper seal. ${ }^{1}$

Endodontic instrumentation has seen a lot of development since it was first ever discovered in the mid-1800s by Edward Maynard by notching round wires from watch springs and then from piano wires, into files that were capable of removing pulp and debris from teeth. .Hand instrumentation, the milestone of endodontic practice in the past, though have lost popularity, still remain an integral part of canal preparation. ${ }^{2}$ Stainless steel root canal instruments clean the canal superficially and can create canal aberrations such as ledges, zips, and elbows. To eliminate these shortcomings of stainless steel instruments, NiTi instruments was developed In 1960 by William Bueller in Silver Springs, Maryland at the United States Naval Ordinance Laboratory. ${ }^{3}$ Canals prepared by NiTi instruments show increased canal cleanliness and less straightening, apical canal transportation, and perforations These benefits are made possible by the flexibility of NiTi instruments and enhanced by specific design feature, which allows a natural canal curvature to be maintained. ${ }^{4}$

During preparation, a canal is shaped by the contact between the instrument and dentin walls. These contacts create many momentary stress concentrations in dentin. ${ }^{4}$ Thus creating craze line or microcracks in root dentin. It seems likely that stresses generated from inside the root canal are transmitted through the root to the surface where they overcome the bonds holding the dentin together. which forms the basis for vertical root fractures. Also, the fracture lines which are advanced into deeper structures permits invasion by the significant amount of bacteria. ${ }^{5}$ which may lead to the formation of biofilms and hence chances of re-infection persist.

Design of file affects strain concentration and apical stress during instrumentation of root canal. Several factors of NiTi files such as different heat treatments, designs, cross-sectional shape, and kinematics may influence the generation of cracks. ${ }^{6}$

ProTaper universal rotary files (Dentsply Maillefer, Ballaigues, Switzerland), are made from a conventional super elastic NiTi wire and have a convex triangular 
cross-sectional design and various percentage tapers that enable an active cutting motion and the removal of relatively more dentin coronally. ${ }^{7}$

K3XF (sybron endo) instruments are made from R-Phase technology and have geometric characteristics of constant taper design with an asymmetrical three-fluted cross-section with unequally spaced flutes and recessive surfaces. $^{8}$

Recently, ProTaper next (Dentsply Maillefer) instruments have been introduced that have an off-centered rectangular design and progressive and regressive percentage tapers on a single file, which is made from M-wire technology. ${ }^{7}$

\section{METHODOLOGY}

Total 75 extracted intact single-rooted mandibular premolar with straight roots were collected from the Department of Oral and Maxillofacial Surgery, College of Dental Sciences, Davangere, Karnataka. Teeth with open apices, fracture lines, anatomic irregularities, teeth with the calcified canal, external or internal resorption were excluded from the study.

\section{Experimental Setup}

Single-rooted extractedmandibular premolar teeth werestored in thymol solution until use. All teeth were being observed under a stereomicroscope to exclude teeth with cracks. To ensure standardization, teeth were sectioned under water cooling with diamond disc $16 \mathrm{~mm}$ from the apex. Roots were covered with a single layer of aluminum foil and were inserted in an acrylic tube. The root was then removed from acrylic tube and foil were be removed. A light body silicon-based material was used to fill the space created by the foil to simulate the periodontal ligament, and the root was immediately repositioned as shown in Figure 1. The apical $3 \mathrm{~mm}$ of

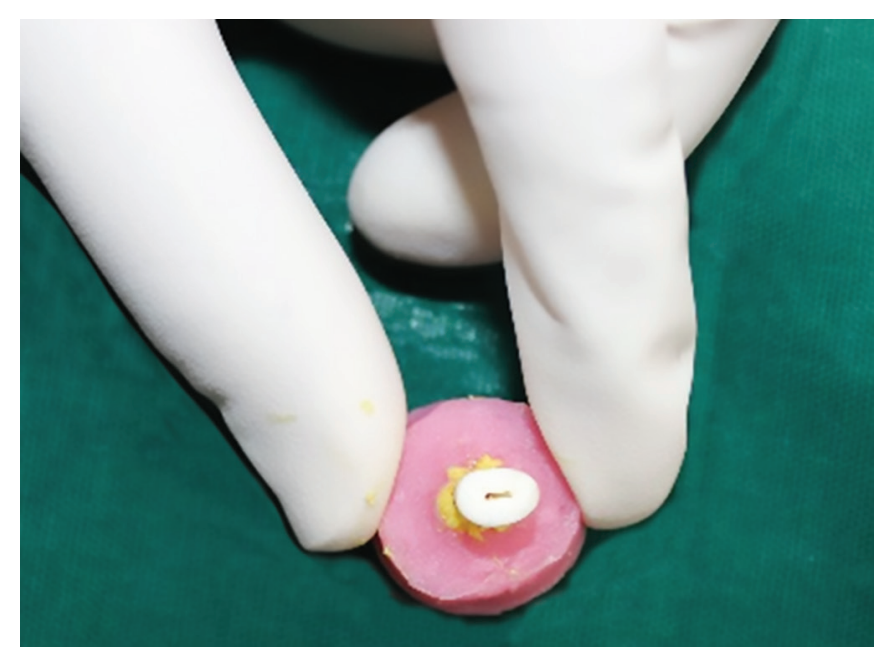

Fig. 1: Preparation of the specimen the root was exposed and immersed in water during instrumentation. The patency of canal was checked and the canal length was measured by inserting a \#8 K-file into the canal until it was visible at the apical foramen. The working length was taken by reducing $1 \mathrm{~mm}$ from the canal length. Apical patency was maintained after each file by inserting \#8 K-file until it appeared at the apical foramen.

The teeth were grouped as follows:

Group 1 ( $n=15)$ : Teeth left unprepared to serve as control $(n=15)$

Group 2 ( $n=15)$ : Teeth instrumented with ProTaper universal (Dentsply Maillefer) using the sequence SX, S1, $\mathrm{S} 2, \mathrm{~F} 1, \mathrm{~F} 2$ at a speed of $250 \mathrm{rpm}$ and torque of $4 \mathrm{Ncm}$ in gentle in and out motion

Group 3 ( $n=15)$ : Teeth instrumented with ProTaper Next (Dentsply Maillefer) using the sequence X1, X2 at a speed of $300 \mathrm{rpm}$ and torque of $4.5 \mathrm{Ncm}$ in gentle in and out motion

Group $4(n=15)$ : Teeth instrumented with K3XF (Sybron Endo) using the sequence 25/.10, 25/.08, 25/.06 K3XF until working length is achieved at a speed of $400 \mathrm{rpm}$ and torque of $3 \mathrm{Ncm}$ in gentle in and out motion.

Canals were irrigated with $1 \%$ sodium hypochlorite solution $12 \mathrm{~mL}$ for each canal. After preparation, the specimen from the prepared group were rinsed with 5 $\mathrm{ml}$ of distilled water.

\section{Specimen Preparation}

All the roots were sectioned perpendicular to the long axis at 3, 6 and $9 \mathrm{~mm}$ from the root apex using a diamond disc under water cooling.

\section{Microscopic Examination}

Stereomicroscopic study: The slices were examined under a stereomicroscope (Olympus-SZX,12, Japan) at 25X magnificationto determine the presence of cracks as shown in Figures 2 to 5.

Each sample was classified into two different categories:

\begin{tabular}{ll}
\hline 'No crack' & $\begin{array}{l}\text { Defined as root dentin without cracks or } \\
\text { craze lines either at the internal surface } \\
\text { of the root wall or the external surface of } \\
\text { the root } \\
\text { Defined as all lines observed on the slices } \\
\text { that either extended from the root canal } \\
\text { 'Crack' } \\
\text { lumen to the dentin or from the outer root } \\
\text { surface into the dentin }\end{array}$ \\
\hline
\end{tabular}

Results were expressed as the number and percentage of cracked roots in each group. A Fischer's exact test was performed to determine statistically significant differences in the appearance of dentinal cracks between 


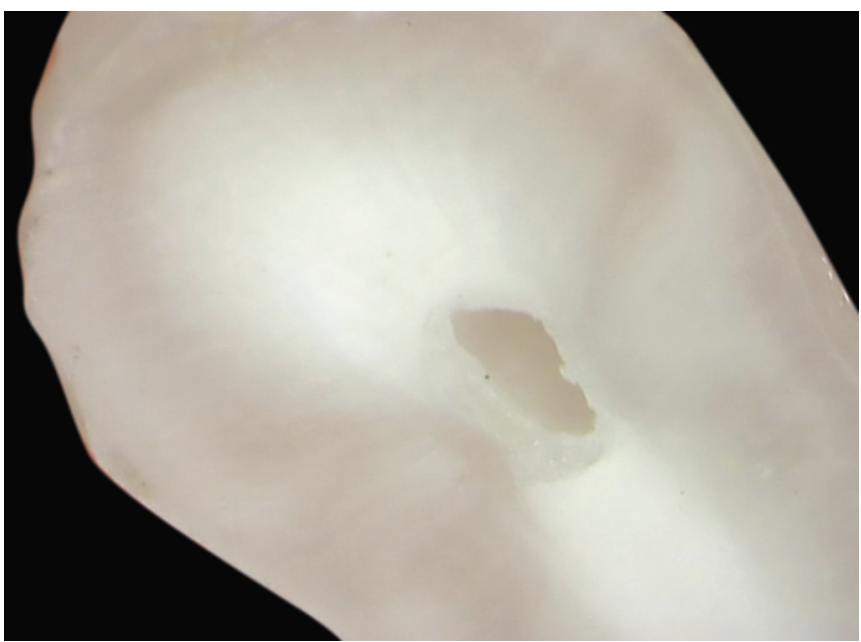

Fig 2: Sections of the root of the unprepared group showing no cracks

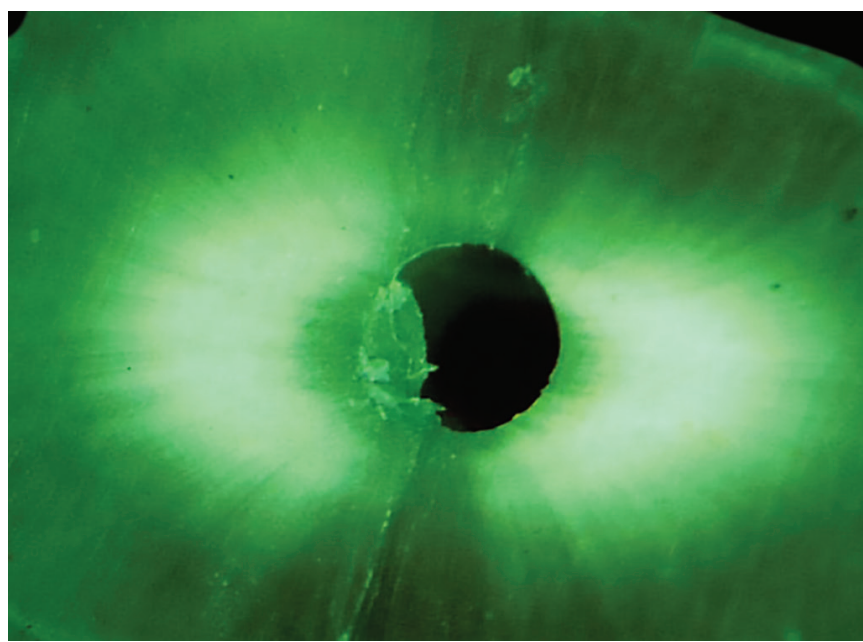

Fig. 4: Sections of root of ProTaper next group showing crack

the experimental groups. Fischer's exact test was also be performed to determine the defects at different horizontal sections in each group.

\section{RESULTS}

Tables 1 to 3 display the number of roots in each group with cracks in the coronal, middle, apical sections respectively. No cracks were observed in the negative control group (unprepared). Vertical root fractures were not observed in any group. The ProTaper next instruments caused fewer cracks $(28 \%)$ than the ProTaper universal instrument $(56 \%)(\mathrm{p}<0.05)$.

\section{DISCUSSION}

Shaping and cleaning of the root canal system is considered a decisive link because shaping determines the efficacy of subsequent procedures.

Traditionally, the shaping of root canals was achieved by the use of stainless steel hand files but had several drawbacks such as they require the use of numerous hand files and drills to adequately prepare the canals,

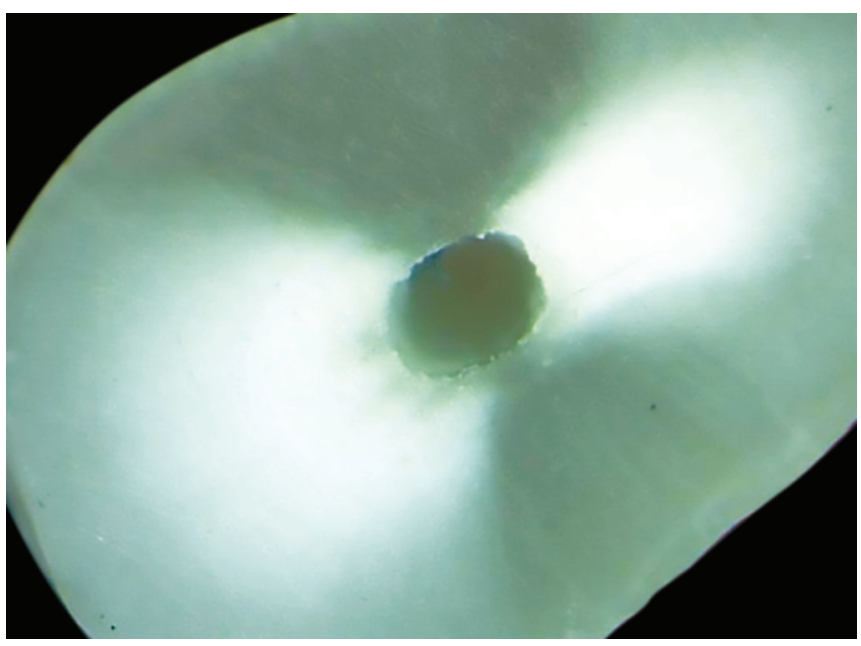

Fig. 3: Sections of the root of ProTaper universal group showing cracks

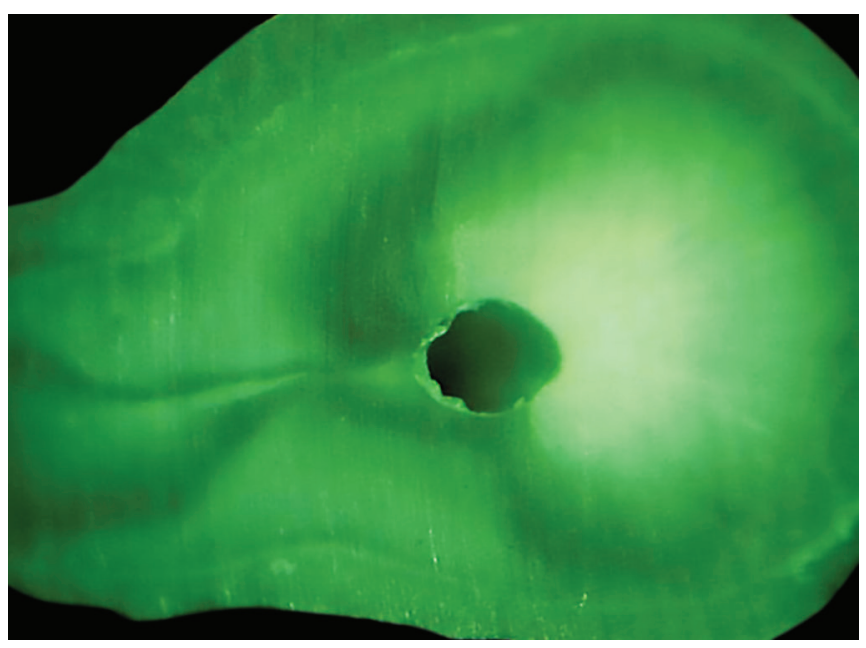

Fig 5: Sections of the root of K3XF showing crack

increased incidence of canal transportation and is timeconsuming. ${ }^{9}$

The NiTi alloy has special characteristics of superelasticity and shape memory. Superelasticity is associated with the occurrence of a phase transformation of the alloy upon application of stress above a critical level, which takes place when the ambient temperature is above the so-called austenite finish temperature of the material. This stress-induced martensitic transformation reverses spontaneously upon release of the stress; the material then returns to its original shape and size. ${ }^{10}$

It has various advantages, such as decreased canal transportation, saves time and better cutting efficiency. However, by its innate behavior in the canal, it may result in more friction, which may increase dentinal defects and microcracks formation in comparison to hand instruments. $^{2}$

Dentinal cracks or root fractures occur when the tensile stress in the root canal wall exceeds the tensile stress of dentin. These defects or microcracks form the basis of vertical root fracture in endodontically treated teeth when subjected to repeated cycles of the mastica- 
Evaluation of Dentinal Crack Initiation after Root Canal Preparation Using three Different Nickel Titanium Rotary Instrument

Table 1: Comparison between unprepared, ProTaper universal, ProTaper next, K3XF

\begin{tabular}{|c|c|c|c|c|c|}
\hline \multirow{2}{*}{ Coronal } & \multicolumn{4}{|l|}{ Group } & \multirow{2}{*}{ Total } \\
\hline & 1 & 2 & 3 & 4 & \\
\hline Crack & 0 & $\begin{array}{l}8 \\
(53.3 \%)\end{array}$ & $\begin{array}{l}4 \\
(26.7 \%)\end{array}$ & $\begin{array}{l}7 \\
(46.6 \%)\end{array}$ & $\begin{array}{l}23 \\
(29.3 \%)\end{array}$ \\
\hline No crack & $\begin{array}{l}15 \\
(100.0 \%\end{array}$ & $\begin{array}{l}7 \\
(46.7 \%)\end{array}$ & $\begin{array}{l}11 \\
(73.3 \%)\end{array}$ & $\begin{array}{l}8 \\
(53.3 \%)\end{array}$ & $\begin{array}{l}52 \\
(70.7 \%)\end{array}$ \\
\hline \multirow[t]{2}{*}{ Total } & 15 & 15 & 15 & 15 & 60 \\
\hline & \multicolumn{4}{|c|}{$\mathrm{p}$-value $=0.01^{*}$} & \\
\hline
\end{tabular}

Table 3: Comparison between unprepared, ProTaper Universal, ProTaper next, K3XF, Hyflex EDM in apical section

\begin{tabular}{llllll}
\hline \multirow{2}{*}{ Apical } & Group & \multicolumn{3}{l}{ Total } \\
\cline { 2 - 5 } & 1 & 2 & 3 & 4 & \\
\hline Crack & 0 & 11 & 5 & 6 & 26 \\
No & 15 & $(73.3 \%)$ & $(33.3 \%)$ & $(40.0 \%)$ & $(36.0 \%)$ \\
crack & $(100.0 \%)$ & $(26.7 \%)$ & $(66.7 \%)$ & $(60.0 \%)$ & $(64.0 \%)$ \\
Total & 15 & 15 & 15 & 15 & 60 \\
& p-value $<0.001^{*}$ & & & \\
\hline
\end{tabular}

Fisher's exact test

${ }^{*} p<0.05$ statistically significant, $p>0.05$ non significant, NS

tory load. In a study done by Vire et al. the prevalence of vertical root fractures was $10.9 \%$ in endodontically treated teeth. ${ }^{6}$

There are a variety of factors that affect the development of forces within the root such as the file taper, file geometry, metallurgy of file, canal morphology, the motions in which the rotary files are used and the thermomechanical treatment.

Thermal treatment of NiTi alloys, such as M-wire (Dentsply), R-phase wire (SybronEndo), and controlled memory wire (DS Dental, Johnson City), has been used to optimize the mechanical properties of the files.

Because NiTi instruments are generally perceived to have high fracture risk during use, new designs have been marketed to lower fracture risks which may also alter the forces on a root during instrumentation and increase dentinal defects that predispose a root to fracture. A study was conducted by Kim et al. which concluded that the stiffer file designs generated higher stress concentrations in the apical root dentin during shaping of the curved canal, which raises the risk of dentinal defects. ${ }^{4}$

As in earlier in vitro studies for evaluation of dentinal microcracks, in the present study acrylic blocks and a silicone impression material were used to simulate bone and periodontal ligament, respectively as shown in Figure 1. This corroborated with a study conducted by Okitsu et al. who suggested that the silicone layer of simulated periodontal ligament will relax and/or proportionate stress and might stress concentration apically. ${ }^{11}$

The stiffness of the file increases as the diameter increases hence In the current study the apical enlarge-
Table 2: Comparison between unprepared, ProTaper universal, ProTaper next, K3XF, Hyflex EDM in the middle section

\begin{tabular}{llllll}
\hline \multirow{2}{*}{ Middle } & Group & & & & \multirow{2}{*}{ Total } \\
\cline { 2 - 5 } & 1 & 2 & 3 & 4 & \\
\hline \multirow{2}{*}{ Crack } & 0 & 8 & 4 & 7 & 23 \\
No & 15 & $(53.3 \%)$ & $(26.7 \%)$ & $(46.6 \%)$ & $(29.3 \%)$ \\
crack & $(100.0 \%)$ & $(46.7 \%)$ & $(73.3 \%)$ & $(53.3 \%)$ & $(70.7 \%)$ \\
Total & 15 & 15 & 15 & 15 & 60 \\
& p-value $=0.01^{*}$ & & & \\
\hline
\end{tabular}

Fisher's exact test

${ }^{*} p<0.05$ statistically significant, $p>0.05$ non-significant, NS

ment was kept a minimum of $0.25 \mathrm{~mm}$ which was constant in all the groups. This is in accordance with a study conducted by Capar et al. which stated that the first crack propagation was associated with larger instruments. This might be attributed to the stiffness of the larger instruments and excessive dentin removal. ${ }^{7}$

In the current study, specimen were sectioned using the diamond disc in low speed with water coolant. No cracks were seen in the unprepared group which indicates that the sectioning methods do not have any effect on the cracks in the sections prepared for stereomicroscopic analysis.

In the present study hight number of dentinal cracks were seen in the ProTaper universal group as shown in Graph 1 which might be attributed to the fact that ProTaper Universal is made of conventional NiTi and motion and design of the file having triangular or modified triangular cross section resulting in less space for collection of dentine chips, thus generating stresses on the root dentinal wall. This is in accordance to a study done Li et al. which stated that the taper of ProTaper universal files used for preparation could contribute to the formation of dentinal cracks. The larger the taper, the more root dentin is removed and the more likely a root fracture would occur. ${ }^{12}$

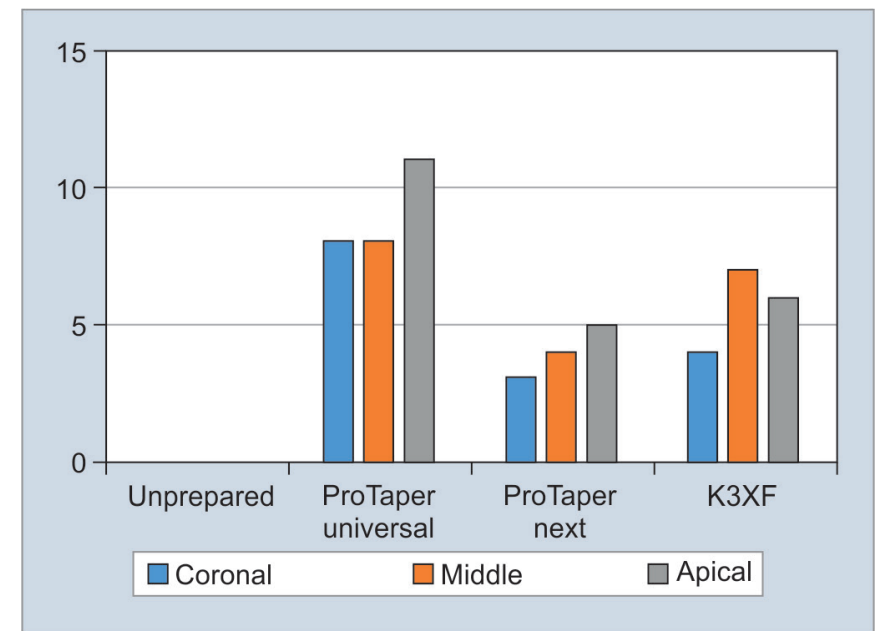

Graph 1: Comparison of the number of the specimen with cracks in unprepared group, ProTaper universal, ProTaper next, K3XF 
In the current study least number of microcracks were observed with ProTaper next group (Graph 1) which might be attributed to The relatively high flexibility of the ProTaper next manufactured with M-wire alloy and controlled memory NiTi wire respectively. The results are in agreement to a study conducted by Capar et al. and stated that endodontic instruments manufactured with M-wire alloy wire have more flexibility than those made from conventional NiTi wire. ${ }^{?}$

The off-centered rectangular design of the ProTaper next instrument may have contributed to the relatively smaller number of cracks in this study. This design generates a swaggering motion, which decreases the screw in effect, dangerous taper lock, and torque on any given file by minimizing the contact between the file and the dentin. ${ }^{13}$

In the current study, the specimen instrumented with the K3XF showed a lower incidence of dentinal microcrack formation as compared to the ProTaper universal group. The results of the present in vitro study are in agreement with the study done by Monga et al which stated that the decrease in the incidence of the crack formation with this continuous rotating system could be due to its peripheral blade relief design of the file which claimed to reduce friction, facilitating its smoother operation. This feature controlled the depth of cut which prevented the files from over-engagement thus, protecting the root dentin from getting more damaged. ${ }^{14}$

In the current study, the incidence of microcracks was not significantly different at coronal and middle third (Tables 1 and 2) but showed a significant difference at the apical third (Table 3) which is in agreement with the study done by Capar et al. which stated that more cracks were also observed in the apical sections ( 0 and $2 \mathrm{~mm}$ ) when compared with the coronal $(8 \mathrm{~mm})$ section. The thin dentinal walls might cause this finding in the apical third. ${ }^{7}$ However, the K3XF files showed a greater incidence of dentinal microcracks at $6 \mathrm{~mm}$ level (Table 2) with the unprepared group. The results of the present in vitro study is in agreement with the study done by Kesim et al. which stated that a variable amount of forces can be transmitted to different parts of the canal wall. Using an initial instrument with greater taper and size in K3XF group may explain why more cracks appeared at $6 \mathrm{~mm}$ level. ${ }^{15}$

In the present studies investigating the development of microcracks after instrumentation have used stereomicroscope for the evaluation of microcracks which is one of the direct observation methods.

\section{Limitations of the study}

The files tested in the study had varying recommended speed and torque values. The use of different speed and torque settings for each file system could be a limitation of the present study. The second limitation of the present study was that during instrumentation it was difficult to standardize the downward force used and the operator blinding. Another possible bias from the clinical situation is the minimal coronal flaring used. Although in accordance with conservative restorative concepts, this could potentially lead to greater apical forces because more aggressiverotary files would be required to achieve the apical third shape.

\section{CONCLUSION}

Within the limitations of this in vitro study the following conclusions can be drawn:

- All NiTi rotary files are capable of initiation of cracks during root canal instrumentation

- The maximum percentage of cracks occur in the apical section

- Maximum percentage of dentinal crack was seen with the ProTaper universal files

- ProTaper next less dentinal crack initiation

- The flexibility of NiTi instruments because heat treatment seems to influence the incidence of microcracks more than other factors

\section{REFERENCES}

1. Peters OA. Current challenges and concepts in the preparation of root canal systems: a review. J Endod. 2004 Aug; 30(8):559-567.

2. Shori DD, Shenoi PR, Baig AR, Kubde R, Makade C, Pandey S. Stereomicroscopic evaluation of dentinal defects induced by new rotary system: "ProTaper NEXT" Jol of Conserv Dent 2015 May-Jun;18(3):210-213

3. Garg S, Mahajan P, Thaman D, Monga P. Comparison of dentinal damage induced by different nickel-titanium rotary instruments during canal preparation: An invitro study. Jol of Conserv Dent 2015 Jul-Aug;18(4):302-305

4. Kim HC, Lee MH, Yum J, Versluis A, Lee CJ, Kim BM. Potential Relationship between Design of Nickel-Titanium Rotary Instruments and Vertical Root FractureJOE 2010 Jul;36(7):1195-1199

5. Iacono F, Pirani C, Generali L, Bolelli G, Sassatelli P, Lusvarghi $\mathrm{L}$, et al. Structural analysis of HyFlex EDM instruments. International Endodontic Journal 2017,Mar;50(3):303-313

6. Tamse A. Vertical root fractures in endodontically treated teeth: diagnostic signs and clinical management. Endodontic Topics 2006 Mar;13(1):84-94.

7. Capar ID, Arslan H, Akcay M, Uysal B. Effects of ProTaper Universal, ProTaper Next, and HyFlex Instruments on Crack Formation in Dentin. JOE 2014 Sept 40 (9):1482-1484

8. Olivieri BJG, Font M G, Sanchez J A G, Cayon MR, Sindreu FD. Danger zone analysis using cone beam computed tomography after apical enlargement with $\mathrm{K} 3$ and $\mathrm{K} 3 \mathrm{XF}$ in a manikin model. J ClinExp Dent. 2016;8(4):e361-7.

9. Shen Y, Zhou HM, Wang Z, Campbell L, Zheng YF, Haapasalo M. Phase Transformation Behavior and Mechani- 
cal Properties of Thermomechanically Treated K3XF NickelTitanium Instruments. J Endod 2013;39:919-923

10. Dane A, Capar ID, Arslan H, Akc, ay M, Uysal B. Effect of Different Torque Settings on Crack Formation in Root Dentin. J Endod 2016;42:304-306.

11. Okitsu M, Takahashi H, Yoshioka T, Iwasaki N, Hideaki. Effective Factors Including Periodontal Ligament on Vertical Root Fractures. Dental Materials Journal, 2005;24(1):66-69.

12. Li SH, Lu Y, Song D, Zhou X, Zheng QH, Gao Y, Huang DM. Occurrence of Dentinal Microcracks in Severely Curved Root Canals with ProTaper Universal, WaveOne, and ProTaper Next File Systems. JOE 2015 Nov;41(11):1875-1879.
13. Venino PM, Citterio CL, Pellegatta A, Ciccarelli M, Maddalone M. A Micro-Computed Tomography Evaluation of the Shaping Ability of Two Nickel-Titanium Instruments, HyFlex EDM and ProTaper Next. JOE 2017 Apr 43;(4):628-632.

14. Monga P, Bajaj N, Mahajan P, Garg S. Comparison of incidence of dentinal defects after root canal preparation with continuous rotation and reciprocating instrumentation. Singapore Dental Journal 2015;3(6):29-33

15. Kesim B, Sagsen B, Aslan T. Evaluation of dentinal defects during root canal preparation using thermomechanically processed nickel-titanium files. Eur J Dent. 2017 AprJun;11(2):157-161. 